\title{
Fixed point theorems in convex metric spaces
}

\section{Mohammad Moosaei*}

\author{
${ }^{*}$ Correspondence: \\ m.moosaei@basu.ac.ir \\ Department of Mathematics, Bu-Ali \\ Sina University, Hamedan, Iran
}

\begin{abstract}
In this paper, we study some fixed point theorems for self-mappings satisfying certain contraction principles on a convex complete metric space. In addition, we investigate some common fixed point theorems for a Banach operator pair under certain generalized contractions on a convex complete metric space. Finally, we also improve and extend some recent results.

MSC: $47 \mathrm{H} 09 ; 47 \mathrm{H} 10 ; 47 \mathrm{H} 19 ; 54 \mathrm{H} 25$
\end{abstract}

Keywords: Banach operator pair; common fixed point; convex metric spaces; fixed point

\section{Introduction}

In 1970, Takahashi [1] introduced the notion of convexity in metric spaces and studied some fixed point theorems for nonexpansive mappings in such spaces. A convex metric space is a generalized space. For example, every normed space and cone Banach space is a convex metric space and convex complete metric space, respectively. Subsequently, Beg [2], Beg and Abbas [3, 4], Chang, Kim and Jin [5], Ciric [6], Shimizu and Takahashi [7], Tian [8], Ding [9], and many others studied fixed point theorems in convex metric spaces.

The purpose of this paper is to study the existence of a fixed point for self-mappings defined on a nonempty closed convex subset of a convex complete metric space that satisfies certain conditions. We also study the existence of a common fixed point for a Banach operator pair defined on a nonempty closed convex subset of a convex complete metric space that satisfies suitable conditions. Our results improve and extend some of Karapinar's results in [10] from a cone Banach space to a convex complete metric space. For instance, Karapinar proved that for a closed convex subset $C$ of a cone Banach space $X$ with the norm $\|x\|_{p}=d(x, 0)$, if a mapping $T: C \rightarrow C$ satisfies the condition

$$
d(x, T x)+d(y, T y) \leq q d(x, y)
$$

for all $x, y \in C$, where $2 \leq q<4$, then $T$ has at least one fixed point. Letting $x=y$ in the above inequality, it is easy to see that $T$ is an identity mapping. In this paper, the above result is improved and extended to a convex complete metric space.

\section{Preliminaries}

Definition 2.1 (see [11]) Let $(X, d)$ be a metric space and $I=[0,1]$. A mapping $W: X \times$ $X \times I \rightarrow X$ is said to be a convex structure on $X$ if for each $(x, y, \lambda) \in X \times X \times I$ and $u \in X$,

$$
d(u, W(x, y, \lambda)) \leq \lambda d(u, x)+(1-\lambda) d(u, y) .
$$

C 2012 Moosaei; licensee Springer. This is an Open Access article distributed under the terms of the Creative Commons Attribution License (http://creativecommons.org/licenses/by/2.0), which permits unrestricted use, distribution, and reproduction in any medium, provided the original work is properly cited. 
A metric space $(X, d)$ together with a convex structure $W$ is called a convex metric space, which is denoted by $(X, d, W)$.

Example 2.2 Let $(X,\|\|)$ be a normed space. The mapping $W: X \times X \times I \rightarrow X$ defined by $W(x, y, \lambda)=\lambda x+(1-\lambda) y$ for each $x, y \in X, \lambda \in I$ is a convex structure on $X$.

Definition 2.3 (see [11]) Let $(X, d, W)$ be a convex metric space. A nonempty subset $C$ of $X$ is said to be convex if $W(x, y, \lambda) \in C$ whenever $(x, y, \lambda) \in C \times C \times I$.

Definition 2.4 (see [3]) Let $(X, d, W)$ be a convex metric space and $C$ be a convex subset of $X$. A self-mapping $f$ on $C$ has a property (I) if $f(W(x, y, \lambda))=W(f(x), f(y), \lambda)$ for each $x, y \in C$ and $\lambda \in I$.

Example 2.5 If $(X,\|\|)$ is a normed space, then every affine mapping on a convex subset of $X$ has the property (I).

Definition 2.6 Let $f, g: X \rightarrow X$. A point $x \in X$ is called

(i) a fixed point of $f$ if $f(x)=x$,

(ii) a coincidence point of a pair $(f, g)$ if $f(x)=g(x)$,

(iii) a common fixed point of a pair $(f, g)$ if $f(x)=g(x)=x$.

$F(f), C(f, g)$, and $F(f, g)$ denote the set of all fixed points of $f$, coincidence points of the pair $(f, g)$, and common fixed points of the pair $(f, g)$, respectively.

Definition 2.7 (see $[12,13])$ The ordered pair $(f, g)$ of two self-maps of a metric space $(X, d)$ is called a Banach operator pair if $F(g)$ is $f$-invariant, namely $f(F(g)) \subseteq F(g)$.

Example 2.8 (i) Let $(X, d)$ be a metric space and $k \geq 0$. If the self-maps $f, g$ of $X$ satisfy $d(g(f(x)), f(x)) \leq k d(g(x), x)$ for all $x \in X$, then $(f, g)$ is a Banach operator pair.

(ii) It is obvious that a commuting pair $(f, g)$ of self-maps on $X$ (namely $f g(x)=g f(x)$ for all $x \in X$ ) is a Banach operator pair, but the converse is generally not true. For example, let $X=\mathbb{R}$ with the usual norm, and let $f(x)=x^{2}-2 x, g(x)=x^{2}-x-3$ for all $x \in X$, then $F(g)=\{-1,3\}$. Moreover, $f(F(g)) \subseteq F(g)$ implies that $(f, g)$ is a Banach operator pair, but the pair $(f, g)$ does not commute.

In [10], Karapinar obtained the following theorems.

Theorem 2.9 (see Theorem 2.4 of [10]) Let $C$ be a closed and convex subset of a cone Banach space $X$ with the norm $\|x\|_{p}=d(x, 0)$, and $T: C \rightarrow C$ be a mapping which satisfies the condition

$$
d(x, T x)+d(y, T y) \leq q d(x, y)
$$

for all $x, y \in C$, where $2 \leq q<4$. Then, $T$ has at least one fixed point.

Theorem 2.10 (see Theorem 2.6 of [10]) Let $C$ be a closed and convex subset of a cone Banach space $X$ with the norm $\|x\|_{p}=d(x, 0)$, and $T: C \rightarrow C$ be a mapping which satisfies the condition

$$
d(T x, T y)+d(x, T x)+d(y, T y) \leq r d(x, y)
$$

for all $x, y \in C$, where $2 \leq r<5$. Then, $T$ has at least one fixed point. 


\section{Main results}

To prove the next theorem, we need the following lemma.

Lemma 3.1 Let $(X, d, W)$ be a convex metric space, then the following statements hold:

(i) $d(x, y)=d(x, W(x, y, \lambda))+d(y, W(x, y, \lambda))$ for all $(x, y, \lambda) \in X \times X \times I$.

(ii) $d\left(x, W\left(x, y, \frac{1}{2}\right)\right)=d\left(y, W\left(x, y, \frac{1}{2}\right)\right)=\frac{1}{2} d(x, y)$ for all $x, y \in X$.

Proof (i) For any $(x, y, \lambda) \in X \times X \times I$, we have

$$
\begin{aligned}
d(x, y) & \leq d(x, W(x, y, \lambda))+d(y, W(x, y, \lambda)) \\
& \leq(1-\lambda) d(x, y)+\lambda d(x, y) \\
& =d(x, y) .
\end{aligned}
$$

Therefore, $d(x, y)=d(x, W(x, y, \lambda))+d(y, W(x, y, \lambda))$ holds.

(ii) Let $x, y \in X$. By the definition of $W$ and using (i), we have

$$
d\left(x, W\left(x, y, \frac{1}{2}\right)\right) \leq \frac{1}{2} d(x, y)=\frac{1}{2} d\left(x, W\left(x, y, \frac{1}{2}\right)\right)+\frac{1}{2} d\left(y, W\left(x, y, \frac{1}{2}\right)\right) .
$$

Therefore,

$$
\frac{1}{2} d\left(x, W\left(x, y, \frac{1}{2}\right)\right) \leq \frac{1}{2} d\left(y, W\left(x, y, \frac{1}{2}\right)\right) .
$$

Similarly,

$$
\frac{1}{2} d\left(y, W\left(x, y, \frac{1}{2}\right)\right) \leq \frac{1}{2} d\left(x, W\left(x, y, \frac{1}{2}\right)\right) .
$$

Therefore, $d\left(x, W\left(x, y, \frac{1}{2}\right)\right)=d\left(y, W\left(x, y, \frac{1}{2}\right)\right)$. Now, from (i), we obtain

$$
d\left(x, W\left(x, y, \frac{1}{2}\right)\right)=d\left(y, W\left(x, y, \frac{1}{2}\right)\right)=\frac{1}{2} d(x, y)
$$

for all $x, y \in C$, and the proof of the lemma is complete.

The following theorem improves and extends Theorem 2.6 in [10].

Theorem 3.2 Let $C$ be a nonempty closed convex subset of a convex complete metric space $(X, d, W)$ and $f$ be a self-mapping of $C$. If there exist $a, b, c, k$ such that

$$
\begin{aligned}
& 2 b-|c| \leq k<2(a+b+c)-|c|, \\
& a d(x, f(x))+b d(y, f(y))+c d(f(x), f(y)) \leq k d(x, y)
\end{aligned}
$$

for all $x, y \in C$, then $f$ has at least one fixed point.

Proof Suppose $x_{0} \in C$ is arbitrary. We define a sequence $\left\{x_{n}\right\}_{n=1}^{\infty}$ in the following way:

$$
x_{n}=W\left(x_{n-1}, f\left(x_{n-1}\right), \frac{1}{2}\right), \quad n=1, \ldots
$$


As $C$ is convex, $x_{n} \in C$ for all $n \in \mathbb{N}$. By Lemma 3.1(ii) and (3.3), we have

$$
\begin{aligned}
& d\left(x_{n}, f\left(x_{n}\right)\right)=2 d\left(x_{n}, x_{n+1}\right), \\
& d\left(x_{n}, f\left(x_{n-1}\right)\right)=d\left(x_{n}, x_{n-1}\right)
\end{aligned}
$$

for all $n \in \mathbb{N}$. Now, by substituting $x$ with $x_{n}$ and $y$ with $x_{n-1}$ in (3.2), we get

$$
a d\left(x_{n}, f\left(x_{n}\right)\right)+b d\left(x_{n-1}, f\left(x_{n-1}\right)\right)+c d\left(f\left(x_{n}\right), f\left(x_{n-1}\right)\right) \leq k d\left(x_{n}, x_{n-1}\right)
$$

for all $n \in \mathbb{N}$. Therefore, from (3.4) and (3.5), it follows that

$$
2 a d\left(x_{n}, x_{n+1}\right)+2 b d\left(x_{n}, x_{n-1}\right)+c d\left(f\left(x_{n}\right), f\left(x_{n-1}\right)\right) \leq k d\left(x_{n}, x_{n-1}\right)
$$

for all $n \in \mathbb{N}$. Let $c$ be a nonnegative number. Using the triangle inequality, (3.4) and (3.5), we obtain

$$
2 c d\left(x_{n}, x_{n+1}\right)-c d\left(x_{n}, x_{n-1}\right) \leq c d\left(f\left(x_{n}\right), f\left(x_{n-1}\right)\right)
$$

for all $n \in \mathbb{N}$. Similarly, for the case $c<0$, we have

$$
2 c d\left(x_{n}, x_{n+1}\right)+c d\left(x_{n}, x_{n-1}\right) \leq c d\left(f\left(x_{n}\right), f\left(x_{n-1}\right)\right)
$$

for all $n \in \mathbb{N}$. Therefore, for each case we have

$$
2 c d\left(x_{n}, x_{n+1}\right)-|c| d\left(x_{n}, x_{n-1}\right) \leq c d\left(f\left(x_{n}\right), f\left(x_{n-1}\right)\right)
$$

for all $n \in \mathbb{N}$. Now, from (3.6) and (3.7), it follows that

$$
2 a d\left(x_{n}, x_{n+1}\right)+2 b d\left(x_{n}, x_{n-1}\right)+2 c d\left(x_{n}, x_{n+1}\right)-|c| d\left(x_{n}, x_{n-1}\right) \leq k d\left(x_{n}, x_{n-1}\right)
$$

for all $n \in \mathbb{N}$. This implies

$$
d\left(x_{n}, x_{n+1}\right) \leq \frac{k-2 b+|c|}{2(a+c)} d\left(x_{n}, x_{n-1}\right)
$$

for all $n \in \mathbb{N}$. From (3.1), $\frac{k-2 b+|c|}{2(a+c)} \in[0,1)$, and hence, $\left\{x_{n}\right\}_{n=1}^{\infty}$ is a contraction sequence in $C$. Therefore, it is a Cauchy sequence. Since $C$ is a closed subset of a complete space, there exists $v \in C$ such that $\lim _{n \rightarrow \infty} x_{n}=v$. Therefore, the triangle inequality and (3.4) imply $\lim _{n \rightarrow \infty} f\left(x_{n}\right)=v$. Now, by substituting $x$ with $v$ and $y$ with $x_{n}$ in (3.2), we obtain

$$
a d(v, f(v))+b d\left(x_{n}, f\left(x_{n}\right)\right)+c d\left(f(v), f\left(x_{n}\right)\right) \leq k d\left(v, x_{n}\right)
$$

for all $n \in \mathbb{N}$. Letting $n \rightarrow \infty$ in the above inequality, it follows that

$$
(a+c) d(v, f(v)) \leq 0 .
$$


Since $a+c$ is positive from (3.1), it follows that $d(v, f(v))=0$. Therefore, $f(v)=v$ and the proof of the theorem is complete.

The following corollary improves and extends Theorem 2.4 in [10].

Corollary 3.3 Let $(X, d, W)$ be a convex complete metric space and $C$ be a nonempty closed convex subset of $X$. Suppose that $f$ is a self-map of $C$. If there exist $a, b, k$ such that

$$
\begin{aligned}
& 2 b \leq k<2(a+b), \\
& a d(x, f(x))+b d(y, f(y)) \leq k d(x, y)
\end{aligned}
$$

for all $x, y \in C$, then $F(f)$ is a nonempty set.

Proof Set $c=0$ in Theorem 3.2.

Theorem 3.4 Let $(X, d, W)$ be a convex complete metric space and $C$ be a nonempty subset of $X$. Suppose that $f, g$ are self-mappings of $C$, and there exist $a, b, c, k$ such that

$$
\begin{aligned}
& 2 b-|c| \leq k<2(a+b+c)-|c|, \\
& a d(g(x), f(x))+b d(g(y), f(y))+c d(f(x), f(y)) \leq k d(g(x), g(y))
\end{aligned}
$$

for all $x, y \in C$. If $(f, g)$ is a Banach operator pair, $g$ has the property $(I)$ and $F(g)$ is a nonempty closed subset of $C$, then $F(f, g)$ is nonempty.

Proof From (3.9), we obtain

$$
a d(x, f(x))+b d(y, f(y))+c d(f(x), f(y)) \leq k d(x, y)
$$

for all $x, y \in F(g)$. $F(g)$ is convex because $g$ has the property (I). It follows from Theorem 3.2 that $F(f, g)$ is nonempty.

Theorem 3.5 Let $(X, d, W)$ be a convex complete metric space and $C$ be a nonempty subset of $X$. Suppose that $f, g$ are self-mappings of $C, F(g)$ is a nonempty closed subset of $C$, and there exist $a, b, c, k$ such that

$$
\begin{aligned}
& 2 b-|c| \leq k<2(a+b+c)-|c|, \\
& a d(g(x), g(f(x)))+b d(g(y), g(f(y)))+c d(g(f(x)), g(f(y))) \leq k d(g(x), g(y))
\end{aligned}
$$

for all $x, y \in C$. If $(f, g)$ is a Banach operator pair and $g$ has the property $(I)$, then $F(f, g)$ is nonempty.

Proof Since $(f, g)$ is a Banach operator pair from (3.12), we have

$$
a d(x, f(x))+b d(y, f(y))+c d(f(x), f(y)) \leq k d(x, y)
$$

for all $x, y \in F(g)$. Because $g$ has the property $(\mathrm{I})$ and $F(g)$ is closed, Theorem 3.2 guaranties that $F(f, g)$ is nonempty. 


\section{Competing interests}

The author declares that he has no competing interests.

\section{Acknowledgements}

The author is grateful to Bu-Ali Sina University for supporting this research.

Received: 28 February 2012 Accepted: 30 August 2012 Published: 25 September 2012

\section{References}

1. Takahashi, T: A convexity in metric spaces and nonexpansive mapping I. Kodai Math. Semin. Rep. 22, 142-149 (1970)

2. Beg, I: An iteration scheme for asymptotically nonexpansive mappings on uniformly convex metric spaces. Nonlinear Anal. Forum 6(1), 27-34 (2001)

3. Beg, l, Abbas, M: Common fixed points and best approximation in convex metric spaces. Soochow J. Math. 33(4), 729-738 (2007)

4. Beg, I, Abbas, M: Fixed-point theorem for weakly inward multivalued maps on a convex metric space. Demonstr. Math. 39(1), 149-160 (2006)

5. Chang, SS, Kim, JK, Jin, DS: Iterative sequences with errors for asymptotically quasi nonexpansive mappings in convex metric spaces. Arch. Inequal. Appl. 2, 365-374 (2004)

6. Ciric, L: On some discontinuous fixed point theorems in convex metric spaces. Czechoslov. Math. J. 43(188), 319-326 (1993)

7. Shimizu, T, Takahashi, W: Fixed point theorems in certain convex metric spaces. Math. Jpn. 37, 855-859 (1992)

8. Tian, YX: Convergence of an Ishikawa type iterative scheme for asymptotically quasi nonexpansive mappings. Comput. Math. Appl. 49, 1905-1912 (2005)

9. Ding, XP: Iteration processes for nonlinear mappings in convex metric spaces. J. Math. Anal. Appl. 132, 114-122 (1998)

10. Karapinar, E: Fixed point theorems in cone Banach spaces. Fixed Point Theory Appl. 2009, Article ID 609281 (2009). doi:10.1155/2009/609281

11. Agarwal, RP, O'Regan, D, Sahu, DR: Fixed Point Theory for Lipschitzian-Type Mappings with Applications. Springer, Heidelberg (2009)

12. Chen, J, Li, Z: Common fixed-points for Banach operator pairs in best approximation. J. Math. Anal. Appl. 336 1466-1475 (2007)

13. Pathak, HK, Hussain, N: Common fixed points for Banach operator pairs with applications. Nonlinear Anal. 69 2788-2802 (2008)

doi:10.1186/1687-1812-2012-164

Cite this article as: Moosaei: Fixed point theorems in convex metric spaces. Fixed Point Theory and Applications 2012 2012:164.

\section{Submit your manuscript to a SpringerOpen ${ }^{\ominus}$ journal and benefit from:}

- Convenient online submission

- Rigorous peer review

Immediate publication on acceptance

- Open access: articles freely available online

- High visibility within the field

- Retaining the copyright to your article 